ADD ON...PRE HOSPITAL CARE

\title{
Pre-hospital Anaesthesia
}

\author{
R Mackenzie, DJ Lockey
}

\section{Introduction}

The decision to rapidly anaesthetise and intubate an unconscious head injured casualty in the resuscitation room is not controversial. Neither is the decision to anaesthetise the casualty with impending airway compromise (e.g. airway burns (1)), ventilatory failure or multiple major injuries. These problems also arise in the pre-hospital environment (2-5) and the full range of basic (6) and advanced (7) airway management interventions should similarly be available. Experienced immediate care practitioners also recognise that pre-hospital anaesthesia may dramatically improve airway management, oxygenation, ventilation, extrication, pain relief and outcome, particularly for those with head and chest injuries, those with prolonged pre-hospital times and those who are trapped (8-13). Anaesthetic skills are also required by those who frequently use analgesic or sedative drugs (14).

Pre-hospital anaesthesia is a potentially dangerous undertaking particularly in the hands of the inexperienced. Casualties with non-lethal injury may die if personnel without the necessary skills, knowledge and experience render them unconscious and apnoeic (15). Tracheal intubation has a low success rate if performed by unskilled personnel and prolonged laryngoscopy may cause harm by predisposing the casualty to vomiting and aspiration, laryngospasm, hypoxia and unwanted physiological reflexes (hypertension, raised intracranial pressure and dysrhythmias).

Although historically in the UK anaesthetic techniques have been exclusively the domain of anaesthetists, this is no longer the case (16.) Emergency physicians and, in other countries, professions allied to medicine, are increasingly developing and using anaesthetic skills in the management of critically injured casualties both in and out of hospital (4,17-20). Much has been written regarding who should perform pre-hospital and emergency department anaesthesia. This article is not about this debate. We aim to provide practical advice for the prehospital doctor who has taken the decision to perform or assist with pre-hospital anaesthesia. We have combined our personal experience with mainstream and research sources.

\section{Training}

Of all the skills required in the pre-hospital environment, it is the induction and maintenance of anaesthesia that poses is perhaps the greatest challenges to the rescuer $\overrightarrow{0}$ and risks for the casualty. In critically ill $\overrightarrow{\vec{\omega}}$ casualties, emergency anaesthesia is $\stackrel{\omega}{\sim}$ associated with a significant frequency of $\overrightarrow{\vec{\Delta}}$ major complications including difficult and failed intubation, oesophageal intubation, pneumothorax, pulmonary aspiration and hypotension (15).

Standardised protocols or operating $\frac{\dot{\omega}}{\omega}$ procedures (SOPs) for pre-hospital o anaesthesia have been developed and have been found to be safe. These cover $O$ indications for anaesthesia, anaesthetic $\stackrel{\circ}{\circ}$ technique, confirmation of tube placement, $\Phi$ failed intubation, complications, monitoring $\tilde{\nabla}$ and transportation. A variety of organizations have published position statements or guidelines that provide a basis for the development of SOPs (4, 17-19). The US National Emergency Airway Course (NEAC) has recently been imported into the UK and provides one of the most comprehensive packages of information, $\fallingdotseq$ protocols and teaching (21). Further practical training and experience with sedated and paralysed patients is essential to safe practice. This can only be obtained in the anaesthetic, operating or emergency room.

In addition to the knowledge and skills $\stackrel{\mathscr{N}}{\vec{F}}$ pertinent to anaesthesia in the emergency setting, training for pre-hospital anaesthesia should address the specific difficulties of $\frac{\rho}{\partial}$ working in a hostile environment with unprepared casualties and limited assistance, equipment and access. These training $\frac{7}{0}$ requirements are summarised in Box 1 .

Box 1. Essential training requirements for pre-hospital anaesthesia

$$
\begin{aligned}
& \text { - Anaesthetic skills and knowledge } \\
& \text { - Awareness of risks and benefits } \\
& \text { - BATLS/ATLS skills and knowledge } \\
& \text { - Familiarity with equipment } \\
& \text { - Supervised pre-hospital experience }
\end{aligned}
$$

\section{The decision to anaesthetise}

Anaesthetising a casualty results in inability to maintain the airway and loss of protective 8 airway reflexes. Thus anaesthetised casualties require scrupulous airway management and $\frac{\bar{\sigma}}{\vec{V}}$ in the emergency setting this invariably 
involves tracheal intubation. It is important to recognise that while there are many lists of indications for emergency intubation in the hospital setting, the risks to the casualty are much higher in the pre-hospital setting. The decision to anaesthetise must, therefore, be a balance between the risks of anaesthetising (including potential delays at the scene) and risks of not anaesthetising. In many circumstances, there are alternative safer strategies such as analgesia, rapid extrication with basic airway management, conscious sedation or regional anaesthesia (14). The distance or time to a resuscitation facility may be so short that to delay at the scene (particularly with penetrating injury) would be inappropriate. There are, however, many circumstances when anaesthesia is indicated in order to maintain or protect the airway and/or maintain adequate ventilation and oxygenation. Thus in deciding whether to anaesthetise and intubate a casualty, the key questions are: (21)

- Is there a failure of airway maintenance?

- Is there a failure of airway protection?

- Is there a failure of ventilation?
- Are there other reasons to anaesthetise?

An algorithm adapted from the NEAC for pre-hospital decision making is illustrated in Figure 1(21). Although simple manoeuvres and adjuncts such as oropharyngeal and nasopharyngeal airways help maintain the airway, these should be regarded as temporary measures. These casualties will all require intubation at some point. The distinction between maintainance and protection of the airway is important. Many critically injured casualties may be able to maintain a patent airway with only minimal intervention. Although airway maintenance with cervical spine control and supplemental oxygen is the key first step in the management of all injured casualties (22), an unconscious casualty with an easily maintained airway and adequate ventilation is still at major risk of passive regurgitation and pulmonary aspiration. The best way to determine whether a casualty is protecting their airway is to look for evidence of spontaneous swallowing or failure to clear blood, saliva or mucous from the oropharynx. The absence of a gag reflex is

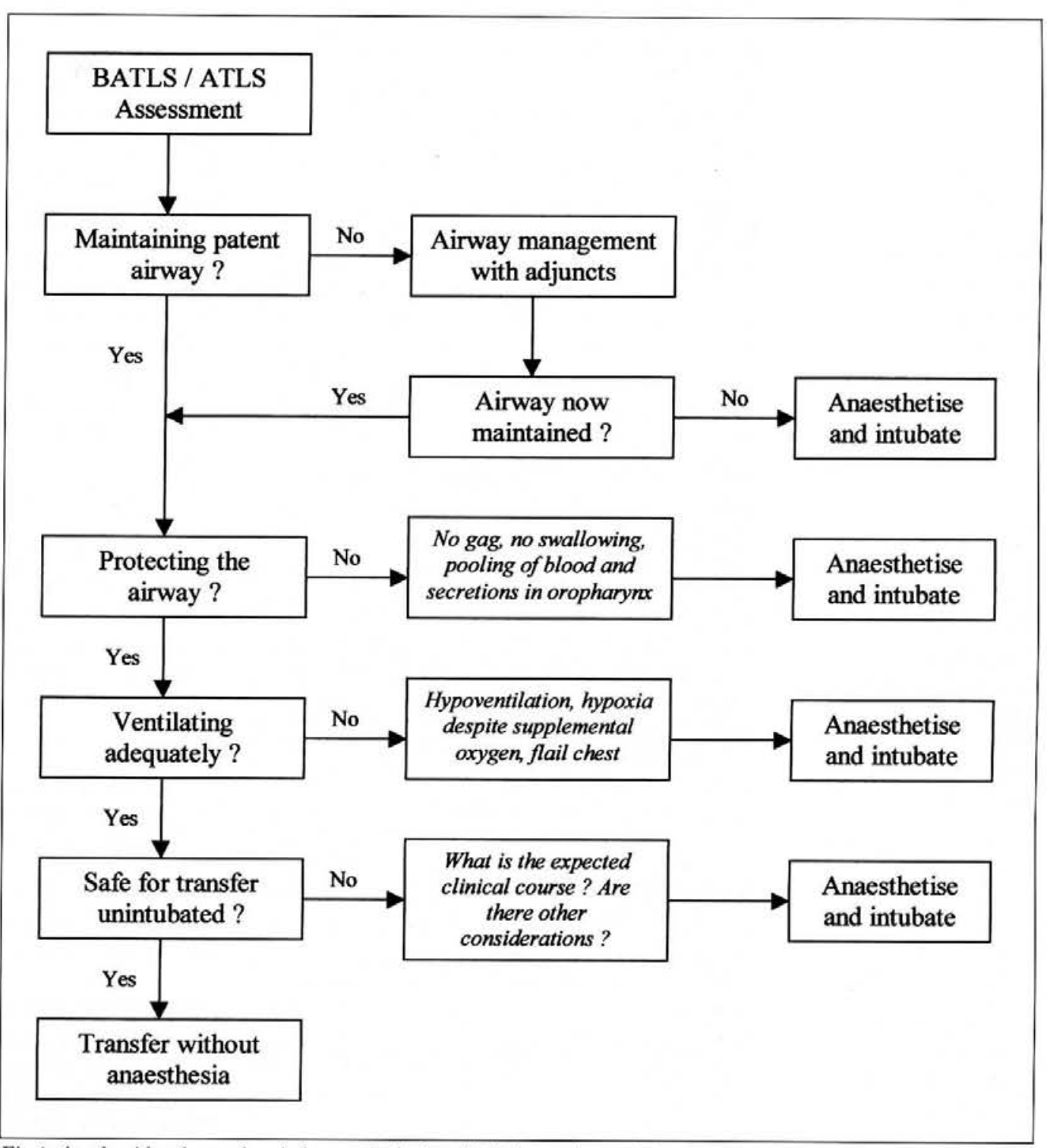

Fig 1. An algorithm for pre-hospital anaesthesia (modified from reference 21). 
neither sensitive nor specific as an indicator of loss of protective airway reflexes and does not accurately predict the need for intubation $(23,24)$

If the ventilation is inadequate or if adequate oxygenation cannot be achieved with supplemental oxygen and a patent airway, then anaesthesia, intubation and ventilation is indicated. Perhaps the most commonly encountered example of this is the conscious casualty with a flail chest. In such circumstances, the anaesthetic is being performed to facilitate ventilation and oxygenation rather than maintain or protect the airway. Again, the proximity of a resuscitation facility and the response to simple measures such as supplemental oxygen, careful analgesia (14) and positioning should be taken into account in making the decision to anaesthetise such patients.

Even if the airway is maintained, the casualty has intact protective reflexes and they are ventilating adequately, there may be circumstances in which pre-hospital anaesthesia is indicated. Removing the work of breathing in a multiply injured casualty may have significant haemodynamic benefits. In casualties with burns (1) or spinal injuries (25), normal initial physiology may rapidly deteriorate in transit. In other cases it may be obvious that the casualty will require anaesthesia and intubation when their 'expected' or 'anticipated' clinical course is considered. Apart from the humanitarian considerations, pre-hospital anaesthesia may actually speed up the resuscitationinvestigation-definitive care process and more than compensate for the additional time on scene. The decision to anaesthetise the casualty with a patent airway, intact protective airway reflexes and adequate ventilation and oxygenation is one of the most important and difficult decisions to make in pre-hospital care and it may require justification to a sceptical in-hospital audience. It also emphasises the importance of training and experience under supervision.

Perhaps the most commonly anaesthetised casualties are those with significant head injuries. Casualties with a Glasgow Coma Score of eight or less (roughly equivalent to $\mathbf{P}$ or $\mathbf{U}$ on the Alert / Responds to Voice / Responds to Pain / Unresponsive scale) are defined as having a major head injury. In these casualties, the importance of maintaining oxygenation and blood pressure has been repeatedly emphasised $(5,26,27)$. In addition, raised intracranial pressure (ICP) is an important cause of death and disability. The development of asymmetric pupils, pupil dilatation, motor posturing or unexplained neurological deterioration are all evidence of a rising ICP. Administration of an anaesthetic and control of the airway and ventilation may reduce the rise in ICP and ultimately improve outcome $(10,13)$.

Trapped casualties have been discussed in a previous article (12). They pose particular problems if an anaesthetic is used to facilitate airway management or extrication. There may be inadequate access to the casualty and many casualties are trapped in the upright position. Most anaesthetic agents are vasodilators and have direct cardiac depressant effects (with the exception of ketamine). Muscle relaxants will reduce the casualty's ability to tamponade haematomas and splint fractures (especially those of the vertebral column). Thus, precipitous falls in blood pressure and further injury may result from anaesthesia in this setting.

\section{Rapid Sequence Intubation}

All pre-hospital anaesthetics should be performed with rapid sequence technique. 'Rapid-sequence induction' was developed as a sequence of specific steps during the induction of anaesthesia in a casualty with a full stomach to minimise the risk of passive regurgitation and aspiration (28). Rapidsequence intubation (RSI) has evolved as a concise version of this technique. The purpose of RSI is to render the casualty unconscious with muscle relaxation in order to intubate the trachea in as short a time as possible and without the use of bag-valvemask ventilation (which may cause gastric distension and increase the risk of aspiration). The NEAC manual usefully breaks down RSI into seven distinct steps based primarily on hospital experience (21). When considering the pre-hospital environment, an additional three steps (patient positioning, plan for failed intubation and packaging and transfer) can be added (Box 2). Although each of these steps is discussed in detail below, the whole process should be very quick with experienced personnel and appropriate equipment.

Box 2. Pre-hospital anaesthesia - the ten P's (modified from reference 21)

\begin{tabular}{l} 
- Preparation \\
- Patient positioning \\
- Pre-treatment \\
- Paralysis with induction \\
- Protection and positioning \\
- Placement with proof \\
- Post-intubation management \\
\hline
\end{tabular}

\section{Preparation}

Training is a key aspect of preparation that has already been emphasised. Preparation also encompasses careful selection and packing of equipment, pre-anaesthetic assessment of the casualty and immediate setting up of equipment at the scene. Equipment for immediate care has also been discussed in a previous article (29). In the context of pre-hospital anaesthesia, the 
specific equipment and drugs chosen may depend to a large extent on training and expertise. The minimum equipment is a laryngoscope (with appropriate blades and spares), a range of cuffed and uncuffed tracheal tubes, lubricant, a syringe to inflate the cuff, a method of securing the tube in place, a stethoscope and a bag-valve-mask device. Ideally, two functioning laryngoscope handles should be available. Blade preference is highly variable but at least two sizes of curved (MacIntosh) and straight (Miller) blades have been recommended (21). A McCoy laryngoscope blade has been found to be particularly useful in the context of limited neck movement (as found in many pre-hospital situations). This has a hinged blade tip that improves the grade of laryngoscopic view when the casualty's neck is immobilised (30-32). A gum elastic bougie improves the success of intubation in difficult circumstances and should always be available (33). A stylet is recommended by NEAC in order to shape the tube prior to intubation. Although of value, use of a stylet prevents use of a bougie and, therefore, may unnecessarily complicate intubation attempts if a poor view is obtained. Appropriately sized Magills forceps and a catheter mount and may also be of particular value. Addition of a disposable passive heat and moisture exchange (HME) filter helps to retain water vapour and heat and maintain the humidity of oxygen enriched air in the trachea. These devices can also prevent contamination of ventilation equipment if they have bacterial filters. A relevant range of tracheal tubes should be packed ready for use but should remain uncut to allow nasotracheal intubation if necessary. 8.0 or $8.5 \mathrm{~mm}$ tubes are generally used for adult males while 7.5 or $8.0 \mathrm{~mm}$ tubes are used for adult females. In younger casualties, tube diameter and length should be calculated (age/ $4+4$ for diameter, age $/ 2+12$ for orotracheal length). A range of alternative sizes around the chosen size should be immediately to hand. Sufficient consumables such as oxygen, drugs, syringes, drawing up needles, saline or water, syringe caps and tube ties should also be available. A suggested pre-hospital anaesthetic equipment list is given in Table 1.

Pre-anaesthetic assessment should focus on the presence of a difficult airway and the likelihood of both successful intubation and successful bag-valve-mask ventilation in the event of failure (34). Risk factors for difficult intubation (difficult laryngoscopy) include abnormalities of the face, mouth and neck such as a short immobile neck, buck teeth, a high arch palate, a receding mandible and inability to sublux the jaw (protrude the lower incisor teeth beyond the upper incisors). Normal mouth opening should be at least four to six centimetres (three fingers) and reduction in this (through injury or anatomy) will also make laryngoscopy difficult. In conscious casualties, the Mallampati classification can be used to predict difficult laryngoscopy (higher grades equating to difficult laryngoscopy). Details of this simple classification will be familiar to those with anaesthetic experience and can be found in standard anaesthetic texts. Difficulty in maintaining the airway and ventilating with bag-valve-mask apparatus

Table 1. Equipment for pre-hospital anaesthesia.

\begin{tabular}{|c|c|}
\hline Equipment & Notes \\
\hline Equipment for Immediate Medical Care & See reference 28 . \\
\hline Oxygen & With high flow regulator \\
\hline Non-rebreathing mask with reservoir & With oxygen tubing \\
\hline Bag-valve-mask apparatus & With reservoir bag and oxygen tubing \\
\hline Nasopharyngeal airways ( 3 sizes) & Prepared for use (tracheal tubes may be used) \\
\hline Oropharyngeal airways ( 4 sizes) & Unwrapped \\
\hline Suction pump & Prepared for use \\
\hline Rigid and flexible suction catheters & Sized appropriately for other airway adjuncts \\
\hline \multicolumn{2}{|l|}{ Wide bore suction tubing } \\
\hline \multicolumn{2}{|l|}{ Venous tourniquet } \\
\hline $\begin{array}{l}\text { Intravenous cannulae } \\
\text { Adhesive tape and dressings }\end{array}$ & Range of sizes. Preferably with side ports \\
\hline \multicolumn{2}{|l|}{ Adhesive tape and dressings } \\
\hline Laryngoscope handle & Preferably two \\
\hline Standard laryngoscope blades & See text \\
\hline McCoy laryngoscope blades & See text \\
\hline \multicolumn{2}{|l|}{ Batteries and bulbs } \\
\hline \multicolumn{2}{|l|}{ Magills forceps } \\
\hline \multicolumn{2}{|l|}{ Gum Elastic Bougie } \\
\hline \multicolumn{2}{|l|}{$20 \mathrm{ml}$ syringe } \\
\hline Intubation accessories & Tie, lubricating jelly, catheter mount etc. \\
\hline Tracheal tubes & Range of sizes, cuffed, uncuffed and uncut \\
\hline \multicolumn{2}{|l|}{ Stylet / introducer } \\
\hline Filter & HME/bacteriostatic \\
\hline \multicolumn{2}{|l|}{ Colorimetric end-tidal $\mathrm{CO}_{2}$ detector } \\
\hline Laryngeal Mask Airway ( 3 sizes) & Single use \\
\hline \multicolumn{2}{|l|}{$50 \mathrm{ml}$ syringe } \\
\hline Surgical cricothyroidotomy set & Scalpel, tracheal dilators, $6.0 \mathrm{~mm}$ ID tracheostomy tube \\
\hline Anaesthetic drug pack & See text. Complete with sufficient needles, syringes etc. \\
\hline \multicolumn{2}{|l|}{ Stethoscope } \\
\hline $\begin{array}{l}\text { Monitoring equipment } \\
\text { Portable ventilator }\end{array}$ & End-tidal $\mathrm{CO}_{2}$ and oximetry as minimum \\
\hline
\end{tabular}


may be predicted by obesity and presence of beard in addition to the features described above. The NEAC describes the 3-3-2 rule to establish extent of mouth opening, position of larynx and size of mandible. Less than 3 finger breadths between the teeth, less than 3 finger breadths between tip of jaw and hyoid and less than 2 finger breadths between the hyoid and the thyroid notch (using the casualty's fingers) indicates a higher risk of difficult intubation (21). By definition, most pre-hospital RSIs will be difficult because of spinal immobilisation or facial injury. This has led to the routine use of McCoy laryngoscope blades and bougies in some pre-hospital systems. The presence of additional risk factors for difficult laryngoscopy or ventilation may influence the decision to proceed in casualties who require an anaesthetic for reasons other than immediate airway maintenance or protection or for ventilatory failure. However, recognition of risk factors will also allow specific equipment for failed intubation (such as a laryngeal mask airway (LMA) and surgical airway equipment) to be prepared for immediate use. From a practical standpoint a detailed assessment of the airway is rarely going to change the decision to proceed. This is because pre-hospital anaesthesia is only likely to be considered in circumstances where patients are already in critical danger.

All of the equipment must be checked immediately prior to RSI. This includes the light sources on the laryngoscope blades (including security of bulbs), the cuff of the tracheal tube and the fit of all equipment such as connectors and catheter mounts. The casualty must have one, preferably two,

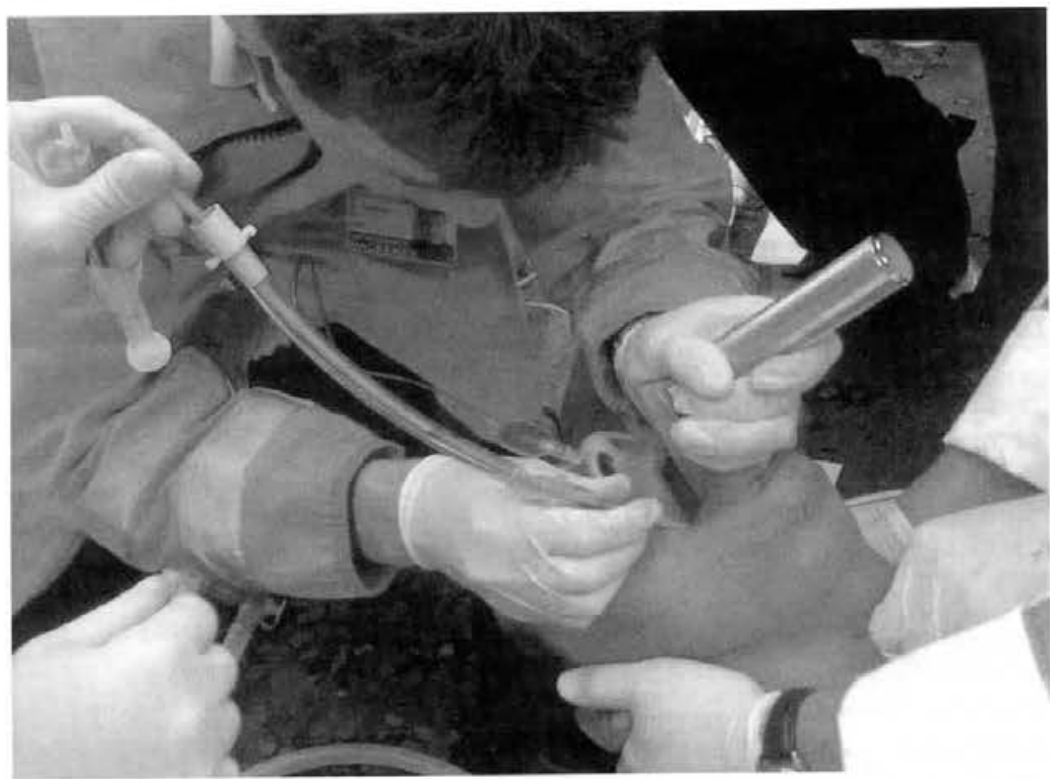

Fig 2. Pre-hospital RSI in a young man with reduced level of consciousness following isolated head injury (cerebral contusion with traumatic sub-arachnoid haemorrhage). Note that four people are involved in the process and that a gum elastic bougie is being used. One person is providing manual in-line immobilisation (MILS) of the cervical spine (the collar has been removed during RSI), another is providing cricoid pressure, a third is passing equipment and controlling the withdrawal of the bougie whilst the fourth person performs the intubation. Reproduced with permission. secure intravenous lines which are functioning and ideally have appropriate preanaesthetic monitoring attached (oximetry, non-invasive blood pressure, ECG). It is recognised that in burns casualties and those who are peripherally shut down that it may not be possible to achieve this. Alternative strategies for airway control and analgesia should be employed if there is no intravenous access unless it is absolutely necessary to anaesthetise the casualty. If this is the case, intra-muscular ketamine is a valuable alternative. In all cases, the drugs to be used should be selected, drawn up and labelled (e.g. with an indelible pen on the syringe barrel) and the equipment laid out such that it is all immediately accessible.

\section{Patient positioning}

Before any attempt at pre-hospital anaesthesia, the casualty should be positioned in as controlled an environment as possible. This may be at the roadside, on an ambulance stretcher or in a resuscitation facility. Once a casualty has been anaesthetised, they are at great danger of further injury or harm during any further lifting, movement or extrication. This may mean that temporising measures such as airway adjuncts are required in the first phase. It is recommended that where possible, casualties should be extricated to a safe environment (perhaps facilitated by analgesia, sedation and regional anaesthetic techniques) and pre-hospital anaesthesia only undertaken when the casualty is in the supine position with relatively easy and full $\left(360^{\circ}\right)$ access. Four people are generally required to perform a safe RSI: one to provide manual immobilisation (with or without the cervical collar), one to provide cricoid pressure (see below), one to intubate and one to give drugs and pass equipment (suction, tracheal tube, bougie, syringe, bagvalve-mask etc.) (Figure 2). The physical space required by rescue personnel may not be available, particularly in the context of entrapment or confined space rescue.

Pre-oxygenation

Early high flow oxygen administration is a cornerstone of pre-hospital management and all trauma casualties should have high inspired oxygen concentrations delivered by a system which best meets their ventilatory pattern and needs. Similarly pre-oxygenation is essential for safe RSI. It should proceed throughout the preparation phase described above. Pre-oxygenation establishes an oxygen reservoir in the lungs, blood and tissues and, if effective, will allow several minutes of apnoea without oxygen desaturation below $90 \%$ and the need to ventilate the casualty. The functional residual capacity of the lungs is approximately $30 \mathrm{ml} / \mathrm{kg}$ and its composition reflects the composition of air. Breathing 100\% oxygen 
for three minutes will replace the dominant nitrogen component with oxygen and provide an oxygen reservoir. A healthy, fully pre-oxygenated $70 \mathrm{~kg}$ adult will maintain oxygen saturation over $90 \%$ for eight minutes after muscle relaxation without ventilation. In contrast, a pre-oxygenated obese $127 \mathrm{~kg}$ adult will desaturate to $90 \%$ in less than three minutes and a $10 \mathrm{~kg}$ child will desaturate to $90 \%$ in less than four minutes. The time for desaturation from $90 \%$ to $0 \%$ is very much shorter: the healthy adult will desaturate from $90 \%$ to $0 \%$ in less than two minutes and the $10 \mathrm{~kg}$ child will do so in 45 seconds $(21,35)$. Pre-oxygenation is therefore an essential component to the success of RSI.

A non-rebreathing mask with reservoir and oxygen flow rate sufficient to meet peak inspiratory demands will deliver between 70 and $80 \%$ inspired oxygen. This is often adequate, provided the casualty is spontaneously breathing and the system is in place for three to five minutes before attempted RSI. Closer to $100 \%$ inspired oxygen can be delivered if the casualty is allowed to breathe through a bag-valve-mask apparatus connected to high flow oxygen. A two handed technique is better at maintaining the seal between the casualty's face and the mask and the casualty will need to be reasonably co-operative. In circumstances where three to five minutes of preoxygenation with a non-rebreathing mask is not possible, eight vital capacity breaths (largest breaths the casualty is capable of taking) through a bag-valve-mask system will provide equivalent pre-oxygenation. It should be apparent that in the absence of supplemental oxygen supplies to facilitate pre-oxygenation, the safety margin for prehospital RSI is very much narrower. If no oxygen is available, alternative management strategies should be considered.

\section{Pre-treatment}

There are two aspects to pre-treatment. The first is the initiation of resuscitation and the control of haemorrhage where possible through direct pressure and splintage. The second concerns the administration of specific drugs to prevent adverse physiological effects associated with RSI. These include atropine to counter reflex bradycardia in children under 10 years and drugs to blunt the sympathetic reflexes to laryngoscopy and the rise in intracranial pressure associated with intubation (e.g. fentanyl, lidocaine and defasciculating doses of competitive neuromuscular blocker). The use of these drugs takes more time and involves further dose calculations (usual dose of atropine is $0.02 \mathrm{mg} / \mathrm{kg}$, usual dose of fentanyl is $3 \mathrm{micrograms} / \mathrm{kg}$ and usual dose of lidocaine is $1.5 \mathrm{mg} / \mathrm{kg}$ ). With the exception of opioid analgesia and atropine, there are conflicting opinions regarding whether pre- treatment drugs should be administered in either the hospital or pre-hospital setting. There is little evidence to support the use of lidocaine or competitive neuromuscular blockers in head injured patients requiring RSI in the emergency department so their pre-hospital use remains uncertain $(20,36-$ 37).

\section{Paralysis (muscle relaxation) with induction}

Once the equipment and personnel have been prepared and the casualty positioned, pre-oxygenated and pre-treated, all those present should be directed to concentrate on the RSI process. A rapidly acting induction agent should be given intravenously in a dose sufficient to produce prompt loss of consciousness. This should be followed immediately by a short acting neuromuscular blocking drug and a fluid bolus. A range of induction agents have been used in the prehospital environment in critically injured casualties. The commonest agents are etomidate, $(19,38)$ ketamine (39) and propofol (40). Propofol needs to be titrated to effect and can cause profound hypotension in hypovolaemic patients. It should only be used by those who are very familiar with its use and it is not ideal for prehospital RSI. In contrast, etomidate is an excellent pre-hospital induction agent due to the rapid onset and recovery, minimal respiratory depression and excellent haemodynamic stability. Intravenous etomidate at 0.2 to $0.3 \mathrm{mg} / \mathrm{kg}$ produces sleep in 5-15 seconds which lasts 5-14 minutes (38). Etomidate has a very minimal effect on cardiovascular parameters, making it suitable for use in the haemodynamically compromised casualty and those at risk for coronary ischaemia. Etomidate also lowers ICP and, in contrast to etomidate infusions, a single dose has not been shown to have clinically significant effects on corticosteriod synthesis (41).

Many pre-hospital doctors will have extensive experience with ketamine and it has been shown to be a safe and effective analgesic and anaesthetic agent in the prehospital environment (14, 42-45). Like etomidate, ketamine preserves haemodynamic stability. It actually increases mean arterial pressure, pulse rate and cardiac output. Thus ketamine is generally contraindicated in casualties in whom an elevation of blood pressure would cause harm (hypotensive patients with penetrating thoracic injuries might be an example). This is why ketamine is considered to be relatively contraindicated in casualties with major head injuries and loss of cerebral autoregulation (even though ketamine may have direct neuroprotective effects). However, any potential rise in ICP is compensated for by a rise in mean arterial pressure and, therefore, cerebral perfusion pressure and this may be particularly relevant to the hypotensive head 
injured casualty. An initial dose of $2 \mathrm{mg} / \mathrm{kg}$ produces deep sedation within 30 seconds for 5 to 10 minutes. Where intravenous access is impossible, the intramuscular route ( 5 to $10 \mathrm{mg} / \mathrm{kg}$ ) can be used (although this is less predictable).

Although some pre-hospital systems use sedation-only techniques for intubating unrelaxed casualties, sedation alone appears to be inadequate to achieve good intubating conditions in a significant proportion of casualties $(4,46)$. The only suitable neuromuscular blocking drug is suxamethonium (succinylcholine). This depolarising (noncompetitive) muscle relaxant does not need to be kept refrigerated (it retains $90 \%$ of its activity for 3 months if stored at room temperature). In a dose of 1.5 to $2 \mathrm{mg} / \mathrm{kg}$ it produces muscle relaxation within 45 to 60 seconds, usually preceded by fasciculation within 15 seconds. Initial return of muscle activity occurs within 3 to 5 minutes and adequate spontaneous ventilation within 8 to 10 minutes. If no intravenous access is possible and the situation is critical, suxamethonium can be given intramuscularly in a dose of $3 \mathrm{mg} / \mathrm{kg}$. Children have higher vagal tone than adults and the antimuscarinic side effects of suxamethonium can cause profound bradycardia in those under the age of 10 (47). This can be avoided with pre-treatment with atropine as discussed above. The same effect can occur in adults with repeated doses. There are numerous reports of successful use of suxamethonium to facilitate tracheal intubation out of hospital $(4,17-19,48)$.

\section{Protection and positioning}

Twenty to thirty seconds after induction, casualties will become apnoeic (longer if peripherally shut down or hypovolaemic). All personnel should already be in position to facilitate safe and effective RSI. In most cases, the casualty will be in the supine position on the ground with manual in-line immobilisation of the cervical spine (Figure 2). Cricoid pressure should be initiated as soon as the casualty begins to lose consciousness to protect against passive regurgitation of gastric contents. This

Box 3. Determination of correct tube placement

Observed

- See the tube passing through the cords (direct visualization)

- Palpation of tube movement within larynx and trachea

- See the chest expand with each ventilation

- Auscultation of breath sounds

- Absence of epigastric sounds with respiration

- See vapour condense in the tube with each ventilation

- Presence of an exhaled tidal volume

- Reservoir bag compliance and refill

- Negative pressure tests (oesophageal detector)

Measured

- Colorimetric Et $\mathrm{CO}_{2}$ detector

- Capnometry

- Capnography

- Improvement in the level of oxygen saturation pressure is achieved by Sellick's manoeuvre (49) and should be maintained throughout $D$ RSI until the position of the tube has been confirmed and the cuff inflated. The aim of cricoid pressure is to compress the $\frac{\mathbb{Q}}{\alpha}$ oesophagus between the cricoid cartilage $\Omega$ ring and the vertebral column without 응 distorting the larynx or moving the neck. One hand should be placed under the neck $\underset{\vec{D}}{\vec{\rho}}$ and the cricoid cartilage gripped between the thumb and forefingers of the other hand. The 등 cricoid ring is then pushed firmly and $\frac{\bar{\sigma}}{\bar{D}}$ directly backwards. If applied incorrectly $\stackrel{\mathbb{Q}}{\varrho}$ (especially on the thyroid cartilage), cricoid pressure can make laryngoscopy more $\vec{\circ}$ difficult. In our experience this is a common problem in the pre-hospital environment. $\vec{\omega}$ The task of cricoid pressure should therefore be given to an experienced provider who has a clear understanding of the procedure.

Some casualties may be profoundly hypoxic $\vec{A}$ or apnoeic prior to intubation. These $\dot{0}$ casualties will usually already be receiving assisted ventilation through a bag-valve-mask apparatus. Cricoid pressure can be applied to these casualties throughout the entire process and during bag-valve-mask ventilation to protect against passive regurgitation.

Placement and proof

Approximately 45 seconds after administration of suxamethonium, the jaw should be tested for flaccidity and laryngoscopy attempted. There is always time to perform laryngoscopy gently and carefully. The glottic aperture should be visualised and either an appropriately sized tracheal tube or the tip of the gum elastic bougie placed. In both cases, the view of the glottis should be maintained while an assistant passes either the tracheal tube or the bougie. If the bougie is used, it should be placed a few centimetres into the trachea. While maintaining the view and keeping the laryngoscope in place, an assistant should then pass a tracheal tube over the bougie. The tube is then progressed into the trachea while the bougie is held by the assistant (Figure 2). This entire process should take place under direct vision. Once the tube is in place, any stylets or bougies should be withdrawn carefully and the cuff inflated. Correct tube placement should then be confirmed immediately.

Confirmation of correct tube placement can be performed by observation and measurement (Box 3). Clinical signs alone are not sufficiently reliable in the pre-hospital environment and tube placement must be confirmed by end-tidal carbon dioxide $\left(\mathrm{EtCO}_{2}\right)$ detection. (50-51) The normal $\mathrm{EtCO}_{2}$ is $5.1 \mathrm{kPa}(38 \mathrm{mmHg})$ at $101.3 \mathrm{kPa}$ $(760 \mathrm{~mm} \mathrm{Hg}$ ) barometric pressure (a $5 \%$ concentration), and normal arterial values for $\mathrm{CO}_{2}$ tension lie between 4.8 and $5.8 \mathrm{kPa}$ (36 and $44 \mathrm{mmHg}$ ). The $\mathrm{EtCO}_{2}$ concentration is so called because it is the $\mathrm{CO}_{2}$ concentration measured at the end of 


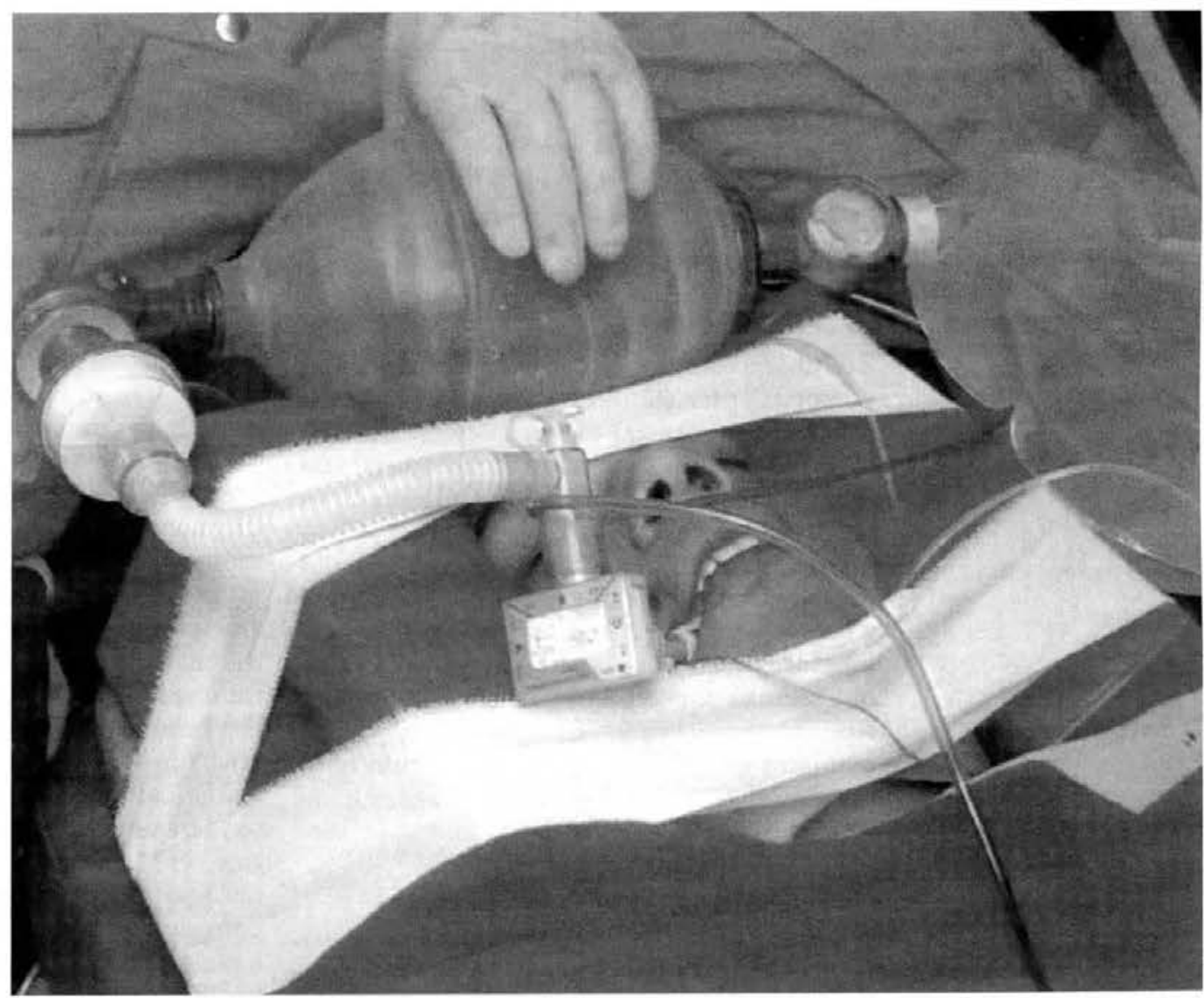

Fig 3. Packaging and transportation of casualty in figure 2. Note the colorimetric end-tidal $\mathrm{CO}^{z}$ detector attached between the tracheal tube and the catheter mount and the filter between the catheter mount and the bag-valve-mask apparatus. This but has been loosened and the casualty is lying on an orthopaedic scoop stretcher. The head blocks provide immobilization for the head and are taped on to the stretcher. Reproduced with permission.

the tidal volume. $\mathrm{EtCO}_{2}$ very closely approximates the alveolar $\mathrm{CO}_{2}$ concentration.

Disposable qualitative $\mathrm{EtCO}_{2}$ detectors that undergo a colour change when expired $\mathrm{CO}_{2}$ passes across their surface are inexpensive, reliable and readily available (Figure 3). The colour of these $\mathrm{pH}$ sensitive indicators typically changes from purple (when exposed to room air) to yellow (when exposed to $4 \% \mathrm{CO}_{2}$ ). Carbonated beverages, expired air forced into the stomach and sodium bicarbonate in the stomach can produce colour changes on the end tidal $\mathrm{CO}_{2}$ detector at least 6 breaths after oesophageal intubation. Consequently, at least 6 tidal volumes should be given before the detector is used to confirm the tracheal tube position. A major disadvantage is that they are of limited value in conditions of poor lighting. Colour changes must also be interpreted with care during low output states such as profound hypovolaemic shock and during cardiopulmonary resuscitation. Pulmonary perfusion is significantly decreased (or absent) in these circumstances and the $\mathrm{EtCO}_{2}$ detector may fail to register a colour change after intubation even if the tube has been correctly placed. Other observations may then be more reliable (Box 3 ). If in any doubt about the correct placement of the tube, it should be removed.
Oesophageal detector devices have been advocated as an alternative to qualitative $\mathrm{EtCO}_{2}$ detector devices. These negative pressure devices rely on differences in the rigidity of tracheal and oesophageal walls. When the operator pulls a plunger or compresses an aspiration bulb connected to a tracheal tube that has been placed in the oesophagus, the aspiration pulls the mucosal wall of the oesophagus against the distal opening of the tracheal tube. As a consequence, either the bulb will not reexpand or the syringe plunger will not pull outward. These devices may be of value when operating in the dark or when a casualty has a very weak or absent pulse but they are generally unreliable (particularly in obese casualties and those with air filled stomachs).

Quantitative $\mathrm{EtCO}_{2}$ measurement devices which digitally display a single numeric value for the highest level of expired $\mathrm{CO}_{2}$ reached during expiration (capnometers) and capnographic waveform monitors that provide a continuous display of $\mathrm{EtCO}_{2}$ over time are effective for both initial confirmation of tracheal tube placement and recognition of subsequent dislodgement. Flexion and extension of the neck during extrication or transport may for example move the tracheal tube up to $5 \mathrm{~cm}$ and there is always a risk of disconnection. Whichever 
Box 4. Actions on failed intubation

( 45 second attempt or desaturation to $\mathrm{SpO}_{2}<90 \%$ at any stage)

- Return to bag-valve-mask with adjuncts

- Change operator position (kneeling/lying down)

- Use aids to intubation (gum elastic bougie)

- BURP manoeuvre

- Cricoid release

- Change operator

- Consider LMA or surgical airway

- Consider waking casualty
$\mathrm{EtCO}_{2}$ detector system is used, the device or sensor adapter should be placed next to the tracheal tube (distal to any catheter mount) to avoid introducing extra dead space and thus potentially falsely high $\mathrm{CO}_{2}$ readings (Figure 3).

Only in extreme circumstances should pre-hospital anaesthesia be performed without $\mathrm{EtCO}_{2}$ monitoring. Additional measures such as pulse oximetry are of value but should supplement rather than replace $\mathrm{EtCO}_{2}$ monitoring. In one study, pulse oximetry and $\mathrm{EtCO}_{2}$ monitoring could have prevented $93 \%$ of preventable anaesthetic incidents in 1097 casualties (52).

\section{Post-intubation management}

Having successfully intubated the casualty and confirmed tube placement, the tube should be secured and ventilation commenced immediately. Post RSI complications such as bradycardia and hypotension should be sought and managed. Bradycardia may result from oesophageal intubation and hypoxia as well as suxamethonium administration. High and low blood pressures may reflect under-and over-sedation respectively. As soon as the tube is secure and ventilation has commenced, anaesthesia should be maintained by intravenous analgesia, sedation and long acting muscle relaxants. It is often at this stage that rescue personnel tend to relax and, as a consequence, control may be lost despite the critical nature of this phase of emergency care.

Analgesia can be provided with intravenous morphine at 0.1 to $0.2 \mathrm{mg} / \mathrm{kg}$ and sedation should be maintained with a benzodiazepine such as Midazolam at $0.2 \mathrm{mg} / \mathrm{kg}$. These should be repeated during transfer at approx $1 / 3$ the initial dose at regular intervals and certainly if any signs of awareness develop (e.g. tachycardia, hypertension, eye watering, sweating, symmetrical pupil dilatation). Long acting muscle relaxants such as pancuronium or vecuronium (at $0.1 \mathrm{mg} / \mathrm{kg}$ ) should also be given and repeated at approximately $1 / 3$ the initial dose every 45 to 60 minutes.

Overzealous positive pressure ventilation by either bag-valve-mask apparatus or portable ventilator may cause harm by increasing intrathoracic pressure and reducing venous return. This may well go unnoticed in the seriously injured casualty who may have lower ventilatory requirements (as a result of lower oxygen consumption and $\mathrm{CO}_{2}$ production). The resulting reduction in cardiac output may be erroneously attributed to other injuries. Six to eight breaths per minute at tidal volumes of approximately $10 \mathrm{ml} / \mathrm{kg}$ may be adequate to maintain oxygenation without impairing cardiac output.

Positive pressure ventilation also predisposes the casualty to development of pneumothoraces that may tension if not identified and treated. All casualties should have a tension pneumothorax deliberately excluded at initial assessment and at any sign of deterioration following ventilation. Immediate chest decompression by needle thoracocentesis is life saving. Pneumothoraces may still reaccumulate after this intervention and definitive decompression via either tube $(11,53)$ or open $(54)$ thoracostomy is indicated if there is any delay to hospital or other appropriate facility. This has been shown to be safe in the pre-hospital environment and is associated with statistically significant improvements in oxygen saturation, blood pressure and pulse rate (11). Gastric decompression with a nasogastric or orogastric tube should also be considered particularly in casualties who have had a period of bag-valve-mask ventilation.

Although many prefer to manually ventilate casualties, the task of intermittently squeezing the bag may compete with other resuscitation priorities and optimal ventilation may not be achieved. Portable ventilators are invaluable in providing smooth, regular and controlled ventilation and lightweight, robust and versatile models are available which can also be used in a contaminated environment $(55,56)$.

\section{RSI failure}

Tracheal intubation can be described as having failed if more than 45 seconds have elapsed or if the casualty's oxygen saturation drops below $90 \%$. Depending on the system, two or three good intubation attempts are generally acceptable provided deliberate steps have been taken to identify and rectify the problem causing the failure and that oxygenation has been maintained between attempts. Most commonly it is poor operator position and technique in an unfamiliar environment (57), an obstructed view due to secretions or abnormal anatomy and excessive or incorrectly applied cricoid pressure that cause problems. Thus in making fresh attempts at laryngoscopy and tube placement, the operator should try to improve whichever aspect may be at fault (Box 4). In all cases, cricoid pressure should be maintained throughout if possible and ventilation commenced with bag-valve-mask apparatus and airway adjuncts between attempts. Aids to intubation such as the gum elastic bougie, McCoy laryngoscope and stylets should all be considered as well as 
Box 5. An aide memoire for pre-hospital anaesthesia

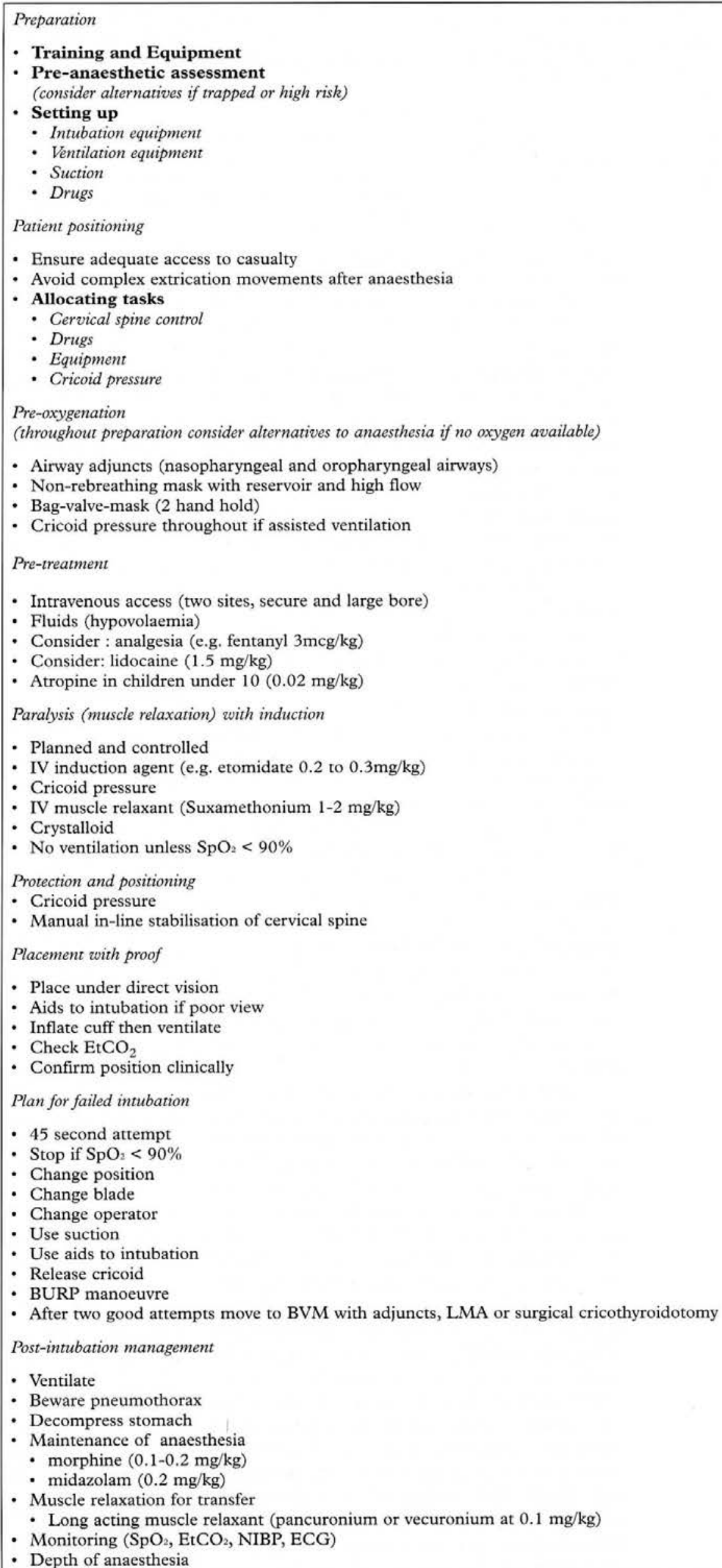

(consider alternatives if trapped or high risk)

- Intubation equipment

- Ventilation equipment

Suction

- Ensure adequate access to casualty

Avoid complex extrication movements after anaesthesia

Allocating task

Drugs

Equipment

Cricoid pressure

(throughout preparation consider alternatives to anaesthesia if no oxygen available)

- Airway adjuncts (nasopharyngeal and oropharyngeal airways)

- Bag-valve-mask (2 hand hold)

Pre-treatmen

- Intravenous access (two sites, secure and large bore

Fluids (hypovolaemia)

Consider: lidocaine $(1.5 \mathrm{mg} / \mathrm{kg})$

Atropine in children under $10(0.02 \mathrm{mg} / \mathrm{kg})$

- Cricoid pressure

- IV muscle relaxant (Suxamethonium 1-2 mg/kg)

Protection and positioning

Cricoid pressure

Placement with proof

Place under direct vision

- Aids to intubation if poor view

Check EtCO

- 45 second attempt

- Stop if $\mathrm{SpO}_{2}<90 \%$

Change positio

Change blade

Use suction

Use aids to intubation

Release cricoid

After two good attempts move to BVM with adjuncts, LMA or surgical cricothyroidotomy

Post-intubation management

entilate

Beware pneumothora

Muscle relaxation for transfer

Monitoring $\left(\mathrm{SpO}_{2}, \mathrm{EtCO}_{2}, \mathrm{NIBP}, \mathrm{ECG}\right)$

Depth of anaesthesia 
Box 5 contimued. An aide memoire for pre-hospital anaesthesia

Packaging and transfer

- Anticipate the problems of moving an anaesthetised casualty

- Transport

- Monitoring in transit

- Maintenance anaesthesia

- Morphine ( $1 / 3$ initial dose if signs of waking/awareness)

- Midazolam (1/3 initial dose if signs of waking/awareness)

- Maintainance of muscle relaxation

- Long acting muscle relaxant (1/3 initial dose every 45-60 mins)

- Communicate with receiving facility

different sizes or configurations of blade. If the cricoid pressure is being applied too vigorously or incorrectly then consider advising or changing the operator. It may also be possible to bring the larynx into a better position by moving it backwards, upwards and to the right (the BURP manoeuvre). Ultimately, some degree of cervical spine movement may be required (up to $15^{\circ}$ ) to achieve intubation.

The keys to the management of failed intubation are early recognition of the problem and not persevering in the face of a desaturating casualty. All personnel who are involved with pre-hospital anaesthesia should be fully conversant with an appropriate failed intubation drill. In most cases, the options are limited to reverting to bag-valvemask ventilation until the casualty recovers from the muscle relaxant, inserting a LMA or proceeding directly to surgical cricothyroidotomy $(4,7,22,58)$. Whichever options are available, the training and experience should be as comprehensive as that required for RSI as these interventions are not without their complications and hazards $(59,60)$.

\section{Transfer to definitive care}

Transfer of anaesthetised patients within and between hospitals is often difficult and renders the patient prone to a wide range of complications. The same problems and principles of management apply when transferring an anaesthetised casualty from the scene to the next level of care. In essence, all tubes and lines must be absolutely secure and someone with the full range of RSI skills must accompany the casualty in the event that they are required to be re-intubated enroute. Careful observation of chest movement, pattern of respiration, absence or presence of sweating or lacrimation and reaction of the pupils is required throughout transfer. Full monitoring should be available which includes pulse oximetry, capnography, ECG and non-invasive blood pressure. Temperature may also be of relevance. Continuous capnography also serves to act as a disconnection alarm if the portable ventilator is not fitted with such a device. At this stage, full documentation should be carried out to both record clinical interventions and vital signs and improve vigilance.

\section{The military setting}

It should be clear from this article that prehospital anaesthesia is a skill and labour intense activity with considerable resource requirements in terms of personnel, equipment, back up and in-transit medical care. It is self-evident that pre-hospital anaesthesia should not be undertaken lightly in the civilian pre-hospital setting in peacetime let alone in the austere environments encountered in military practice. Clearly there will be some casualties who would benefit clinically from prehospital anaesthesia and this should be undertaken where the medical support and evacuation capabilities are sufficient.

\section{Summary}

Effective management of the airway may have the greatest impact on mortality and morbidity of all pre-hospital interventions. The administration of a pre-hospital anaesthetic may not only facilitate effective management and protection of the airway but may also be fundamental to maintaining adequate ventilation and reducing times to definitive treatment for casualties who are trapped and those with major chest and head injuries. Pre-hospital anaesthesia is a highly skilled technique that requires considerable training and experience. Inappropriate attempts to anaesthetise critically injured casualties may prove fatal if the operator does not have the requisite knowledge, skills and equipment. For those that do, this article provides an operational framework within which pre-hospital anaesthesia can be developed (Box 5).

This is the fifth article in the add on series in prehospital care. The series is edited by Maj $R$ Mackenzie. Maj Df Lockey is a consultant in anaesthesia and intensive care medicine at Frenchay Hospital, Bristol and a Fellow in Prehospital care at the Royal London Hospital. Maj $R$ Mackenzie is a Specialist Registrar in Accident and Emergency Medicine in East Anglia and a practising immediate care doctor. While every effort has been made to ensure correct drug dosages are quoted, readers should always check these before use.

\section{References}

1. Treharne LJ, Kay A.The initial management of acute burns. F R Army Med Corps 2001;147:198-205. 
2. Stocchetti N, Furlan A, Volta F. Hypoxaemia and arterial hypotension at the accident scene in head injury. F Trauma 1996;40:764-7.

3. Cooke RS, McNicholl BP, Byrnes DP. Early management of severe head injury in Northern Ireland. Injury 1995;26:395-7.

4. National Association of EMS Physicians Standards and Clinical Practice Committee. Position Paper: Pre-hospital Rapid Sequence Intubation. Prehosp Emerg Care 2001;5:40-48.

5. Chesnut RM, Marshall LF, Klauber MR, et al. The role of secondary brain injury in determining outcome from severe head injury. If Trauma 1993;34:216-22.

6. European Resuscitation Council. Guidelines for the basic management of the airway and ventilation during resuscitation. Resuscitation 1996;31:187-200.

7. European Resuscitation Council. Guidelines for the advanced management of the airway and ventilation during resuscitation. Resuscitation 1996;31:201-30.

8. Deakin CD. Preventable pre-hospital death from trauma. Pre-hospital Immediate Care 1997;1:198203.

9. Lockey DJ. Prehospital trauma management. Resuscitation 2001;48:5-15.

10. Winchell RJ, Hoyt DB. Endotracheal intubation in the field improves survival in patients with severe head injury. Arch Surg 1997;132:592-7.

11. Coats TJ, Wilson AW, Xeropotamous N. Prehospital management of patients with severe thoracic injury. Injury 1995;26:581-585.

12. Mackenzie R, Sutcliffe R. Pre-hospital Care: The trapped patient. F R Army Med Corps 2000;146:3946.

13. Kelly AM. Does advanced airway management in the field by paramedics improve patient outcome? A review of the literature. Prehospital Immediate Care 2001;5:16-18.

14. Mackenzie R. Analgesia and sedation. f R Army Med Corps 2000;146:117-127.

15. Schwartz DE, Matthay MA, Cohen NH. Death and other complications of emergency airway management in critically ill adults. A prospective investigation of 297 tracheal intubations. Anesthesiology 1995;82:367-76.

16. Gwinnutt $C$. The interface between anaesthesia and emergency medicine. Emerg Med f 2001;18:325-26.

17. Mackay CA, Terris J, Coats TJ. Prehospital rapid sequence induction by emergency physicians: is it safe? Emerg Med f 2001;18:20-4.

18. Graham CA, Meyer AD. Prehospital emergency rapid sequence induction of anaesthesia. I Accid Emerg Med 1997;14:219-21.

19. Swanson ER, Fosnocht DE, Neff RJ. The use of etomidate for rapid-sequence intubation in the air medical setting. Prehosp Emerg Care 2001;5:1426.

20. Butler JM, Clancy M, Robinson N, Driscoll P. An observational study of emergency department rapid sequence intubation. Emerg Med $g$ 2001;18:343-8.

21. Walls RM, Luten RC, Murphy MF, Schneider RE (eds). Manual of emergency airway management. Philadelphia: Lippincott, Willams and Wilkins, 2000.

22. Battlefield Advanced Trauma Life Support. Airway management and ventilation. $\mathcal{F} R$ Army Med Corps 2000;146:218-27.

23. Moulton C, Pennycook A, Makower R. Relation between Glasgow coma scale and the gag reflex. BMF 1991;303:1240-1.

24. Davies AE, Kidd D, Stone SP et al. Pharyngea sensation and gag reflex in healthy subjects. Lancet 1995;345:487-8.

25. Spinal Injuries. In: Greaves I, Porter K, Ryan J. Trauma Care Manual. London; Arnold, 2001:12441

26. Procaccio F, Stocchetti N, Citerio G, et al. Guidelines for the treatment of adults with severe head trauma (part I). Initial assessment; evaluation and pre-hospital treatment; current criteria for hospital admission; systemic and cerebral monitoring. $f$ Neurosurg Sci 2000;44:1-10.
27. American Association of Neurological Surgeons. Guidelines for the management of severe head injury. I Neurotrauma 1996;13:639-734.

28. Stept WI, Safar P. Rapid induction-intubation for prevention of gastric-content aspiration. Anesth Analg 1970;49:633-6.

29. Mackenzie R, Greaves I, Sutcliffe RC. Equipment for Immediate Medical Care. 7 R Army Med Corps 2000;146:232-42.

30. Uchida T, Hikawa Y, Saito Y et al. The McCoy levering laryngoscope in patients with limited neck extension. Canadian fournal of Anaesthesia 1997;44:674-6.

31. Laurent SC, de Melo AE, Alexander-Williams JM. The use of the McCoy laryngoscope in patients with simulated cervical spine injuries. Anaesthesia 1996;51:74-5.

32. Gabbott DA. Laryngoscopy using the McCoy laryngoscope after application of a cervical collar. Anaesthesia 1996;51:812-4

33. Nolan JP, Wilson ME. Orotracheal intubation in patients with potential cervical spine injuries. An indication for the gum-elastic bougie. Anaesthesia 1993;48:630-3.

34. Vaughan RS. Predicting difficult intubation. In Latto IP, Vaughan RS (eds). Difficulties in tracheal intubation. London:WB Saunders, 1997:79-89.

35. Benumof J, Dagg R, Benumof R. Critical haemoglobin desaturation will occur before return to an unparalysed state following $1 \mathrm{mg} / \mathrm{kg}$ intravenous succinylcholine. Anesthesiology 1997;87:979-82.

36. Butler J, Jackson R. Lignocaine pre-medication prior to rapid sequence induction in head injuries. http://www.bestbets.org.

37. Clancy $M$, Halford S, Walls $R$, Murphy $M$. In patients with head injuries who undergo rapid sequence intubation using succinylcholine, does pretreatment with a competetive neuromuscular blocking agent improve outcome? Emerg Med $f$ 2001;18:373-5.

38. Bergen JM, Smith DC. A review of etomidate for rapid sequence intubation in the emergency department. F Emerg Med 1997;15:221-30.

39. Gofrit ON, Leibovici D, Shemer J, Henig A, Shapira SC. Ketamine in the field: the use of ketamine for induction of anaesthesia before intubation in injured patients in the field. Injury 1997;28:41-3.

40. Heath KJ, Samra GS, Davis GE, Wilmink AB, Wilson AW. Blood pressure changes in head-injury casualties during pre-hospital anaesthesia. Injury 1994;25 Suppl 2:B7-8.

41. Burton JH. Etomidate. Acad Emerg Med 1995;2:724.

42. Basics Monograph on Immediate Care No 2: Pain Releif (2nd ed.) British Association for Immediate Care, 1995.

43. Sherwood N. Analgesia and pain relief. In: Greaves I, Porter KM (eds). Prehospital medicine: the principles and practice of Immediate Care. London: Arnold 1999

44. Austin TR, Tamlyn RSP. Ketamine. A revolutionary anesthetic agent for the battle casualty. I Roy Army Med Corps 1972;118:15-23.

45. Cottingham R, Thomson $\mathrm{K}$. Use of ketamine in prolonged entrapment. $f$ Accid Emerg Med 1994;11:189-91.

46. Adnet F, Jouriles NJ, Le Toumelin et al. Survey of out-of-hospital emergency intubations in the French pre-hospital medical system: a multicenter study. Ann Emerg Med 1998;32:454-9.

47. Sing RF, Reilly PM, Rotondo MF, Lynch MJ, McCans JP, Schwab CW. Out-of-hospital rapidsequence induction for intubation of the pediatric patient. Acad Emerg Med 1996;3:41-5.

48. Wayne MA, Friedland E. Prehospital use of succinylcholine: a 20-year review. Prehosp Emerg Care 1999;3:107-109.

49. Sellick BA. Cricoid pressure to prevent regurgitation of stomach contents during induction of anaesthesia. Lancet 1961:404-6. 
50. National Association of EMS Physicians Standards and Clinical Practice Committee. Position Paper: Verification of endotracheal tube placement following intubation. Prehosp Emerg Care 1999;3:248-50.

51. Falk JL, Sayre MR. Confirmation of airway placement. Prehosp Emerg Care 1999;3:273-278.

52. Tinker JH, Dull DL, Caplan RA, Ward RJ, Cheney FW. Role of monitoring devices in prevention of anesthetic mishap: a closed claims analysis. Anesthesiology 1989;71:541-6.

53. Schmidt U, Stalgo $M$, Gericii T, Blauth $M$, Maull $\mathrm{KI}$, Tscherne $\mathrm{H}$. Chest tube decompression of blunt chest injuries by physicians in the field: effectiveness and complications. F Trauma 1998;44:98-101.

54. Deakin CD, Davies G, Wilson A. Simple thoracostomy avoids chest drain insertion in prehospital trauma. F Trauma 1995;39:373-4.

55. Roberts MJ, Bell GT, Wong LS. The CompPAC and PortaPAC portable ventilators bench tests and field experience. I R Army Med Corps 1999;145:73-7.
56. Gaffney P, Johnson G. Mechanical ventilators in prehospital care. Prehospital Immediate Care 2001;5:1923.

57. Adnet F, Cydulka RK, Lapandry C. Emergency tracheal intubation of patients lying supine on the ground: influence of operator body position. Can 7 Anaesth 1998;45:266-9.

58. Gwinnutt CL. Alternatives to endotracheal intubation in airway management. $\mathcal{F} \mathrm{Br}$ Assoc Immed Care 1996;19:37-41.

59. Morris A, Lockey D, Coats T. Fat necks: modification of a standard surgical airway protocol in the pre-hospital environment. Resuscitation 1997;35:253-4.

60. Miklus RM, Elliott C, Snow N. Surgical cricothyrotomy in the field: experience of a $\mathbb{Q}$ helicopter transport team. I Trauma 1989;29:506-8.

61. Sloane C, Vilke GM, Chan TC, Hayden SR, Hoyt $\mathrm{DB}$, Rosen P. Rapid sequence intubation in the field versus hospital in trauma patients. J Emerg Med 2000;19:259-64. 